\title{
HUBUNGAN KEPEMILIKAN SAHAM APOTEKER PADA APOTEK DENGAN PELAKSANAAN GOOD PHARMACY PRACTICE (GPP) OLEH APOTEKER
}

\section{(THE CORRELATION OF SHAREHOLDING OF PHARMACISTS IN PHARMACIES WITH THE IMPLEMENTATION OF GOOD PHARMACY PRACTICES (GPP) BY PHARMACISTS)}

\author{
PUTU EKA ARIMBAWA ${ }^{1 \bullet}$, DEWA AYU PUTU SATRYA DEWI ${ }^{1}$, NI MD. D. SHANTINI SUENA ${ }^{2}$ \\ ${ }^{1}$ Prodi Farmasi Klinis, Institut Ilmu Kesehatan Medika Persada Bali \\ ${ }^{2}$ Prodi DIII Farmasi, Akademi Farmasi Saraswati Denpasar
}

\begin{abstract}
Abstrak: Good Pharmacy Practice (GPP) adalah praktik farmasi, oleh apoteker, untuk menciptakan konsep kualitas layanan kesehatan yang baik. Dalam membuat apotek untuk melakukan GPP, apoteker dapat bekerja sama dengan pemilik apotek (non-apoteker) dalam bentuk saham apotek. Kerjasama tersebut tidak akan menjadi masalah jika tidak bertentangan dengan GPP. Penelitian ini merupakan penelitian cross-sectional. Penelitian dilakukan terhadap 71 apoteker di Kota Denpasar. Data dikumpulkan pada Februari-April 2017 dengan kuesioner dan dianalisis dengan uji chi-square. Hasil penelitian menunjukkan bahwa tidak ada hubungan yang signifikan antara kepemilikan apotek dan aspek kesejahteraan pasien $(\mathrm{p}=0,13, \mathrm{OR}=2,13)$ dan manajemen $(\mathrm{p}=0,51, \mathrm{OR}=1,38)$. Ada hubungan yang signifikan antara aspek kontribusi apoteker $(\mathrm{p}=$ $0,04, \mathrm{OR}=2,76)$ dan kerjasama dengan dokter $(\mathrm{p}=0,02, \mathrm{OR}=3,30)$. Secara keseluruhan, ada hubungan yang signifikan $(\mathrm{p}=0,03$, OR $(\mathrm{CI} 95 \%)=3,02(1,08-8,41))$. Kepemilikan saham apotek oleh apoteker menunjukkan adanya hubungan yang signifikan antara aspek kontribusi apoteker dan kerja sama dengan dokter. Kepemilikan saham akan meningkatkan kepercayaan dan jaminan keamanan apoteker, terutama saat membantu dokter dalam memberikan informasi tentang obat-obatan.
\end{abstract}

Kata kunci: Apotek, Apoteker, GPP, Kepemilikan Saham, Non-apoteker.

\begin{abstract}
Good pharmacy practices (GPP) are pharmaceutical practices, by pharmacists, to create a quality concept of healthy service. In making pharmacies to do GPP, pharmacists can work with non-pharmacists in the form shareholding. Cooperation would not be a problem if it respected did not conflict with the GPP. This research is a cross-sectional study. The study was conducted on 71 randomly selected pharmacists in Denpasar City. Data was collected between February-April 2017 with questionnaires and analyzed by a Chi-Square Test. The results from the study showed that there is no significant correlation between shareholding of pharmacies between the aspects of patient welfare $(\mathrm{p}=0.13, \mathrm{OR}=2.13)$ and management $(\mathrm{p}=0.51, \mathrm{OR}=1.38)$. There is a significant relationship between the aspects of pharmacist contributions $(\mathrm{p}=0.04, \mathrm{OR}=2.76)$ and cooperation with physicians $(\mathrm{p}=0.02, \mathrm{OR}=3.30)$. Overall, there is a significant relationship $(\mathrm{p}=0.03$, OR $(\mathrm{CI} 95 \%)=$ $3.02(1.08-8.41)$ ). The shareholding in pharmacies by pharmacists shows that there is a significant relationship for aspects of pharmacist contributions and cooperation with a physician. The share ownership will increase pharmacists' confidence and security guarantees, especially when helping physicians in providing information on medicines.
\end{abstract}

Keyword: shareholding, pharmacies, pharmacists, non-pharmacist, GPP

\section{PENDAHULUAN}

Good pharmacy practice (GPP) adalah praktik farmasi oleh apoteker untuk menciptakan konsep kualitas layanan kesehatan yang baik. GPP di apotek terdiri dari aspek kesejahteraan pasien, manajemen, kontribusi apoteker dan kerjasama dengan dokter [WHO, 1996]. pelaksanaan GPP oleh apoteker belum dilakukan dengan baik, terutama di apotek. Studi sebelumnya juga mengungkapkan bahwa kurang dari sepertiga apoteker menasihati pasien secara teratur. Hanya seperempat apoteker yang mengklaim bahwa mereka melaporkan kesalahan pengobatan dan sebagian besar apotek (92\%) tidak secara rutin menyimpan catatan pasien [Hasan et all, 2012]. Apoteker bekerja di apotek kurang dari 20 jam setiap minggu. Jadi, banyak apotek dikelola oleh seorang non-apoteker yang tidak mengerti GPP [Hermansyah et all, 2012].

\footnotetext{
•Email korespondensi: eka_apoteker@yahoo.co.id
} 
Apoteker dapat bekerja sama dengan pemilik apotek (non-apoteker) untuk membangun fasilitas kesehatan apotek. Kerjasama apoteker dengan nonapoteker bisa dalam bentuk saham dan pelayanan. Kepemilikan saham berarti masing-masing pihak memberikan persentase sumbangan yang terdiri dari uang, bangunan, atau logistik dan tercantum dalam perjanjian tertulis. Pengaturan apotek dalam bentuk saham akan lebih banyak diatur oleh pemegang saham paling tinggi. Sedangkan kerjasama dalam bentuk pelayanan, apoteker hanya sebagai pegawai [Setiawan, 2007].

Hasil wawancara dengan 71 apoteker di Kota Denpasar antara bulan Februari-April 2017 menemukan bahwa 39 apotek dimiliki oleh nonapoteker, 21 apotek kerjasama antara apoteker dan non apoteker (14 apoteker memiliki kepemilikan saham >50\%), serta 11 apotek dimiliki oleh apoteker sendiri. Berdasarkan data tersebut, jumlah kepemilikan saham apotek lebih dari 50\% lebih banyak dimiliki oleh non-apoteker. Pelaksanaan GPP oleh seorang non-apoteker tidak akan menjadi masalah jika menghormati kode etik farmasi. Tapi, jika keputusan itu lebih berorientasi keuntungan, maka akan terjadi pelanggaran terhadap pelaksanaan GPP.

Jumlah Kepemilikan saham apotek yang sedikit oleh apoteker menyebabkan aktivitas di apotek lebih diatur oleh non-apoteker, dan penerapan GPP tidak akan dilakukan, sehingga membuat peneliti tertarik melihat hubungan antara kepemilikan saham dan penerapan GPP oleh apoteker.

\section{METODE PENELITIAN}

Penelitian ini merupakan penelitian korelasi. Penelitian dilakukan dengan desain survei crosssectional dan mengambil sampel dari populasi pada bulan Februari-April 2017, dengan kuesioner. Teknik sampling yang digunakan adalah purposive sampling.

Perhitungan sampel yang digunakan adalah sebagai berikut

$$
\begin{aligned}
\mathrm{n}= & \frac{z_{1-\infty / 2}^{2} \mathrm{P}(1-\mathrm{P}) \mathrm{N}}{\mathrm{d}^{2}(\mathrm{~N}-1)+z_{1-\alpha / 2}^{2} \mathrm{P}(1-\mathrm{P})} \\
= & \frac{(0,95)^{2} 0,5(1-0,5) 241}{} \\
& 0,1^{2}(241-1)+(0,95)^{2} 0,5(1-0,5) \\
& =69 \text { Sampel, }
\end{aligned}
$$

Jadi jumlah minimal sampel yang digunakan sebesar 69, dalam penelitian ini menggunakan 71 sampel.

Keterangan

$$
\begin{array}{ll}
\mathrm{n} & =\text { Sampel } \\
\mathrm{P} & =\text { Peluang } \\
\mathrm{N} & =\text { Populasi } \\
\mathrm{d} & =\text { Limit error atau presisi absolut } \\
\mathrm{Z}^{2}{ }_{1-\alpha / 2} & =\text { Derajat kepercayaan }
\end{array}
$$

Jumlah sampel yang digunakan adalah 71 apoteker dengan kriteria inklusi memiliki izin praktik sebagai apoteker di Kota Denpasar dan bekerja di apotek selama satu tahun. Kriteria Ekslusi (bukan bagian dari sampel) adalah apoteker yang tidak memiliki ijin praktek yang bekerja di apotek. Analisis data yang digunakan adalah uji chi-square.

\section{HASIL}

\section{Karakteristik sampel, kepemilikan saham di apotek, dan pelaksanaan aspek GPP oleh apoteker}

Karakteristik sampel (usia, jenis kelamin, pekerjaan selain apoteker, status pernikahan), kepemilikan saham di apotek oleh apoteker dan aspek penerapan GPP (kesejahteraan pasien, manajemen, kontribusi apoteker, dan kerjasama dengan dokter) ditunjukkan pada tabel 1 . Karakteristik sampel ini bertujuan untuk melihat prevalensi besaran sampel.

Hasil karakterisitik sampel didapatkan data umur yang $\leq 27$ tahun sebanyak $38(53,5 \%)$ dan $>27$ tahun sebanyak 33 (46,5\%), sedangkan untuk jenis kelamin didapatkan hasil jumlah laki-laki 25 $(35,2 \%)$ lebih sedikit dibandingkan dengan jumlah perempuan sebesar $46(64,8 \%)$. Untuk pekerjaan selain apoteker, yang tidak memeiliki pekerjaan selain apoteker penanggung jawab sebanyak 48 $(67,6 \%)$, kemudian yang memiliki pekerjaan selain apoteker sebanyak $23(33,4 \%)$.

Hasil univariat untuk karakterisitik variable dependen didapatkan untuk aspek kesejahteraan pasien kurang baik sebesar $37(52,1 \%)$ lebih banyak dibandingkan dengan kesejateraan pasien baik 34 (47,9\%). Aspek manajemen dengan status kurang baik sebesar $35(49,3 \%)$ lebih sedikit dibandingkan dengan status baik 36 (50,7\%). Untuk aspek kontribusi peran apoteker jumlah status kurang baik lebih sedikit 34 (47,9\%) dibandingkan status baik sebesar $37(52,1 \%)$. Aspek kerjasama dengan dokter untuk peningkatan terapi pengobatan dengan status kurang baik 
sebesar $36(50,7 \%)$ lebih banyak dibandingkan kurang baik sebesar 35 (49,3\%). Untuk pelaksanaan Good Pharmacy Practice (GPP) yang kurang baik sebesar $35(49,3 \%)$ lebih sedikit dibandingkan yang baik sebesar $36(50,7 \%)$.

Tabel 1. Karakterisitik Sampel, Kepemilikan Saham di Apotek, dan Pelaksanaan Aspek GPP oleh Apoteker

\begin{tabular}{|c|c|}
\hline Karakteristik Sampel & $f(\%)$ \\
\hline \multicolumn{2}{|l|}{ Umur } \\
\hline$\leq 27$ Tahun & $38(53,5)$ \\
\hline > 27 Tahun & $33(46,5)$ \\
\hline \multicolumn{2}{|l|}{ Jenis Kelamin } \\
\hline Pria & $25(35,2)$ \\
\hline Wanita & $46(64,8)$ \\
\hline \multicolumn{2}{|l|}{ Pekerjaan selain apoteker } \\
\hline Ya & $23(33,4)$ \\
\hline Tidak & $48(67,6)$ \\
\hline
\end{tabular}

Status pernikahan Ya

$29(40,8)$

Tidak

$42(59,2)$

\begin{tabular}{lc}
$\begin{array}{c}\text { Kepemilikan Saham Apotek } \\
\text { oleh apoteker }\end{array}$ & $\mathbf{f ( \% )}$ \\
\hline $\begin{array}{l}\text { Kepemilikan saham } \leq 50 \% \\
\text { Kepemilikan saham }>50 \%\end{array}$ & $46(64,8)$ \\
\hline Aspek Pelaksanaan GPP & $\mathbf{f ( \% )}$ \\
\hline $\begin{array}{l}\text { Kesejahteraan Pasien } \\
\text { Kurang baik }\end{array}$ & $37(52,1)$ \\
Baik & $34(47,9)$ \\
Manajemen & \\
$\quad$ Kurang baik & $35(49,3)$ \\
$\quad$ Baik & $36(50,7)$ \\
Kontribusi apoteker & \\
$\quad$ Kurang baik & $34(47,9)$ \\
Baik & $37(52,1)$ \\
Kerjasama dengan dokter & \\
$\quad$ Kurang baik & $36(50,7)$ \\
Baik & $35(49,3)$ \\
\hline
\end{tabular}

Tabel 2. Uji Chi-square Karakteristik Sampel, Kepemilikan Saham, dan Aspek Implementasi GPP oleh Apoteker Berdasarkan Hasil Penilaian Kuesioner

\begin{tabular}{|c|c|c|c|c|c|c|c|c|}
\hline \multirow{3}{*}{$\begin{array}{c}\text { Karakteristik } \\
\text { dan } \\
\text { kepemilikan } \\
\text { saham }\end{array}$} & \multicolumn{8}{|c|}{ Pelaksanaan GPP } \\
\hline & \multicolumn{2}{|c|}{$\begin{array}{c}\text { Kesejahteraan } \\
\text { pasien }\end{array}$} & \multicolumn{2}{|c|}{ Manajemen } & \multicolumn{2}{|c|}{ Kontribusi apoteker } & \multicolumn{2}{|c|}{$\begin{array}{c}\text { Kerjasama } \\
\text { dengan dokter }\end{array}$} \\
\hline & $\boldsymbol{P}$ & OR & $\boldsymbol{P}$ & OR & $p$ & OR & $p$ & OR \\
\hline Umur & 0,39 & 0,66 & 0,07 & 0,42 & 0,92 & 0,95 & 0,89 & 0,94 \\
\hline Jenis Kelamin & 0,98 & 0,99 & 0,73 & 1,18 & 0,62 & 0,78 & 0,73 & 0,84 \\
\hline $\begin{array}{l}\text { Pekerjaan } \\
\text { selain apoteker }\end{array}$ & 0,60 & 0,76 & 0,39 & 0,65 & 0,61 & 0,77 & 0,39 & 1,53 \\
\hline $\begin{array}{l}\text { Status } \\
\text { Pernikahan }\end{array}$ & 0,36 & 1,55 & 0,73 & 1,17 & 0,59 & 1,29 & 0,73 & 0,84 \\
\hline $\begin{array}{l}\text { Kepemilikan } \\
\text { saham apotek } \\
>50 \% \text { oleh } \\
\text { apoteker }\end{array}$ & 0.13 & 2,13 & 0.51 & 1,38 & $0.04 *$ & 2,76 & $0.02 *$ & 3,30 \\
\hline
\end{tabular}

\section{PEMBAHASAN}

Hubungan kepemilikan saham di apotek dengan aspek kesejahteraan pasien dan manajemen

Kepemilikan saham di apotek oleh apoteker akan dapat menciptakan perilaku yang tidak memperioritaskan keuntungan, dengan kata lain, hal itu akan mengutamakan kesejahteraan pasien. Hasil $\mathrm{p}$ diperoleh $0,13(\mathrm{OR}=2,13)$. Artinya tidak ada hubungan yang signifikan antara kepemilikan saham dengan aspek kesejahteraan pasien. Fokus seorang apoteker dalam praktik profesionalisme adalah konseling, menanggapi gejala penyakit umum dan promosi kesehatan [Adepu dan Nagavi, 2009]. Keberhasilan profesinya didasarkan pada pelayanan dari apa yang dibutuhkan seorang pasien. Imbalan untuk seorang profesional sejati adalah ketika dia menyediakan dan melakukan layanan untuk pasien [Crisholm et all, 2006].

Aspek manajemen terkait erat dengan sistem adminsitrasi untuk mencegah terjadinya pengadaan 
barang berlebih dan menciptakan pengendalian yang optimal. Pengawasan yang efektif dan efisien dapat melaksanakan pengadaan layanan tepat waktu, harga yang benar, jaminan kualitas (spesifikasi) dan kuantitas yang tepat (volume). Hasil penelitian $\mathrm{p}$ diperoleh $0,51 \quad(\mathrm{OR}=1,38)$. Artinya tidak ada hubungan yang signifikan antara kepemilikan saham dengan aspek manajemen. Pengelolaan obat disesuaikan dengan kebutuhan masyarakat apotek. Jadi, pengelolaan obat tanpa memperhatikan kebutuhan masyarakat sekitar akan berdampak pada hilangnya keuntungan apotek itu sendiri. Selain itu, aspek pengelolaan harus sesuai dengan peraturan perundang-undangan yang berlaku [Permenkes, 2014].

\section{Hubungan kepemilikan saham di apotek dengan aspek kontribusi apoteker dan kerjasama bersama dokter.}

Perbedaan antara kinerja perusahaan, yang disusun oleh manajemen dibandingkan dengan pemiliknya berpengaruh terhadap kinerja perusahaan. Perusahaan yang dikendalikan oleh pemiliknya akan menghasilkan kinerja perusahaan yang lebih baik [Crossan, 2017]. Hasil penelitian menunjukkan bahwa $\mathrm{p}=0,04$ (OR $=2,76)$. Ini berarti ada hubungan yang signifikan antara kepemilikan saham dengan aspek kontribusi apoteker, yang berarti bahwa kepemilikan saham dapat membantu mengurangi permasalahan antara pemilik dan apoteker. Proporsi kepemilikan saham, di pihak manajer lebih dari pemilik lainnya, akan meningkatkan kontribusi dan kemajuan dalam perusahaan [Kumar, 2004].

Kepemilikan saham di apotek oleh apoteker akan meningkatkan pendapatan mereka yang dapat memperbaiki pelayanan farmasi di apotek [Sherilyn et all, 2014]. Hasilnya menunjukkan $\mathrm{p}=$ $0,02(\mathrm{OR}=3,30)$. Artinya ada hubungan yang signifikan kepemilikan saham dengan aspek kerjasama bersama dokter. Tambahan saham akan meningkatkan kemakmuran pemegang saham terutama apoteker dan akan mampu mengurangi konflik kerja internal dalam bisnis[Bernsten et all, 2010]. Hal ini membuat apoteker memiliki pendapatan lebih karena pendapatan mereka tidak berasal dari satu sumber daya, tetapi juga berasal dari pemilikan saham.

Hubungan kepemilikan saham di apotek dan penerapan GPP oleh apoteker

Apotek idealnya harus dimiliki oleh apoteker untuk dapat memberikan memberikan pelayanan semaksimal mungkin kepada pasien. Jika kepemilikan saham apoteker lebih tinggi daripada non-apoteker, maka itu bisa memberi rasa aman bagi apoteker dalam bekerja. Perasaan aman ini bisa membuat apoteker mengembangkan kreativitas dalam hal manajemen dan pelayanan [Akmal et all, 2013]. Terpenting apoteker bisa berinteraksi dengan pasien kapan saja dan layanan lebih optimal [Bonnarens, 2009]. Apoteker yang bekerja dengan non-apoteker sebagai karyawan cenderung berorientasi pada keuntungan, karena seorang non-apoteker melakukan intervensi dalam pengelolaan dan pelayanan obat-obatan. Akhirnya, hal itu dapat menyebabkan pelayanan apotek tidak memenuhi standar yang ditetapkan [Suhartono et all, 2015].

Penelitian ini memiliki keterbatasan karena mengukur kepemilikan saham oleh apoteker sebagai satu-satunya faktor pelaksana GPP. Perlu dilakukan penelitian lebih lanjut terhadap faktor lain yang mempengaruhi GPP. Selain itu juga perlu dilakukan penelitian mengenai seberapa besar kepuasan pasien terhadap pelaksanan GPP

\section{SIMPULAN}

Kepemilikan saham apotek oleh apoteker menunjukkan adanya hubungan yang signifikan dengan pelaksanaan GPP. Kepemilikan saham akan meningkatkan kepercayaan dan jaminan keamanan apoteker, terutama dalam meningkatkan kontribusi dan kerjasama dengan dokter.

\section{UCAPAN TERIMA KASIH}

Ucapan terima kasih diberikan semua pihak yang membantu dalam penyelesaian jurnal ini terutama kepada apoteker Kota Denpasar yang sudah berpatisipasi dalam penelitian ini.

\section{DAFTAR PUSTAKA}

Adepu R, Nagavi BG. 2009. Attitudes and Behaviors of Practicing Community Pharmacists Towards Patient Counselling. [ONLINE] Available at https://www. ncbi. nlm. nih.gov/pmc /articles/PMC2865787/). [Accessed 15 April 2017]. 
Akmal D, Syahrul, Aulia. Analisis Faktor-Faktor yang Mempengaruhi Kepuasan Kerja Apoteker yang Bekerja di Apotek di Kota Padang. Jurnal Sains dan Teknologi Farmasi, 2013; 18:1-8.

Bernsten C, Andersson K, Gariepy Y, Simoens S. Acomparative Analysis Of Remuneration Models For Pharmaceutical Professional Services. Journal Health Policy 95. 2010; 1: 1-9.

Bonnarens. 2009. Aplication In Independet Community Pharmacy in SP. Desselle, DP. Zgarticle. Pharmacy managemen Essentials for all practice settings 2nd Ed. The MC Graw-Hill Companies, Inc. New York ; 553-71

Crisholm, MA, Cobb H, McDuffie C, Kennedy W. Instrutctional Design and Assesment Development of an Instrument to Measure Profesionalis. American Journal of Pharmaceuitical Education, 2006; 70: 1-6

Crossan, K. The Theory of the Firm and Alternative Theories of Firm Behaviour: A Critique. [ONLINE] Available at http:// managementjournals. com/journals ig/vol1/21-1-1-2.pdf. [Accessed 15 April 2017].

Hasan S, Sulieman H, Chapman CB, Stewart K, Kong D. Community pharmacy services in the United Arab Emirates. International Journal of Pharmacy Practice. 2012; 20: 218-225.

Hermansyah A, Sukorini AI, Setiawan CD, Priyandani Y. The Conflict Between Professional and Non-Profesisional Work Of Community Pharmacist In Indonesia.
Journal Pharmacy Practice, 2012; 10: 33 39

Kumar J. Does Ownership Structure Influence Firm Value ? Evidence from India. The Journal of Entrepreneurial Finance \& Business Ventures, 2004; 2: 61-93.

Permenkes. 2014. Standar Pelayanan Kefarmasian di Apotek. [ONLINE] Available at http:// binfar.kemkes.go.id/?wpdmact $=$ process $\&$ $\underline{\mathrm{did}}=$ NDEwLmhvd Gxpbms. [Accessed 15 April 2017].

Setiawan B. 2007. Pelaksanaan Perjanjian Kerja Sama Antara Pemilik Sarana Apotik (PSA) Dengan Apoteker Pengelola Apotik (APA) di Kota Semarang. [ONLINE] Available at http://eprints. undip.ac.id/15394/1/ Bambang Setiawan. pdf. [Accessed 15 April 2017].

Sherilyn KD, Houle, Kelly A, Grindrod, Trish C, Ross T, Tsuyuki. Services Paying Pharmacists For Patient Care: A Systematic Review of Remunerated Pharmacy Clinical care. Canadian Pharmacists Journal / Revue des Pharmaciens du Canada, 2014; 147: 209232

Suhartono, Athiyah U, Utami W. Analisis Hubungan Profesionalisme Apoteker Dengan Praktek Asuhan Kefarmasian Studi Kasus Terapi Diabetes Di Apotek Wilayah Kabupaten Sidoarjo. Jurnal Ilmu Kefarmasian Indonesia September, 2015; 13: 166-173.

WHO. Good Pharmacy Practice (GPP) in Community and Hospital Pharmacy Settings. Geneva. 1996. 


\section{Lampiran Kuesioner}

\section{KUESIONER}

\section{BERIKANLAH TANDA V PADA KOLOM YANG TERSEDIA}

Jenis kelamin $\square$ Laki-laki $\square$ Perempuan

Pekerjaan selain sebagai apoteker di apotek tempat melakukan praktek profesi

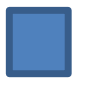

Pengusaha
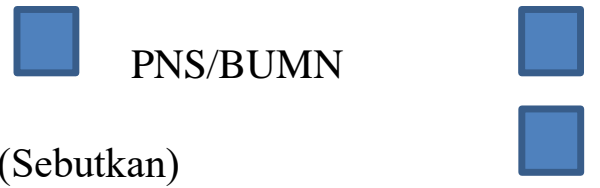

Karyawan swasta

Lainya (Sebutkan)

Tidak ada

Kepemilikan saham di tempat apotek bekerja

Tidak ada

$1-20 \%$

$21-50 \%$

Umur dalam tahun $=$

Status Pernikahan

Sudah menikah
$51-80 \%$

$81-100 \%$

Belum Menikah 


\begin{tabular}{|c|c|c|c|c|c|}
\hline \multirow{2}{*}{\multicolumn{2}{|c|}{$\begin{array}{l}\text { Good Pharmacy Practice } \\
\text { (GPP) }\end{array}$}} & \multicolumn{4}{|c|}{ JAWABAN } \\
\hline & & \multirow{2}{*}{$\begin{array}{l}\text { Tidak } \\
\text { baik }\end{array}$} & \multirow{2}{*}{$\begin{array}{l}\text { Kurang } \\
\text { Baik }\end{array}$} & \multirow[t]{2}{*}{ Baik } & \multirow{2}{*}{$\begin{array}{c}\text { Sangat } \\
\text { Baik }\end{array}$} \\
\hline $\begin{array}{l}\text { ASPEK } \\
\text { KESEJAHTERAAN } \\
\text { PASIEN }\end{array}$ & $\begin{array}{l}\text { Apoteker berinteraksi dengan } \\
\text { pasien dan memperlakukan } \\
\text { dengan rasa hormat yang sama } \\
\text { tanpa melihat latar belakang } \\
\text { social serta kemampuan } \\
\text { membayar }\end{array}$ & & & & \\
\hline & $\begin{array}{l}\text { Apoteker memberikan alternatif } \\
\text { pilihan untuk pemenuhan } \\
\text { kebutuhan pasien sesuai dengan } \\
\text { kemampuan membayar }\end{array}$ & & & & \\
\hline & $\begin{array}{l}\text { Dalam hal obat yang tidak } \\
\text { tersedia, pemenuhan kebutuhan } \\
\text { obat di usahakan dari tempat lain } \\
\text { tanpa biaya tambahan }\end{array}$ & & & & \\
\hline & $\begin{array}{l}\text { Apoteker membangun hubungan } \\
\text { professional dengan dokter } \\
\text { untuk mendapatkan terapi yang } \\
\text { efektif kepada pasien }\end{array}$ & & & & \\
\hline & $\begin{array}{l}\text { Apoteker melakukan konsultasi } \\
\text { dan kerjasama dengan } \\
\text { apoteker/apotek lainya dalam } \\
\text { memberikan terapi kepada } \\
\text { pasien }\end{array}$ & & & & \\
\hline \multirow[t]{4}{*}{$\begin{array}{l}\text { ASPEK } \\
\text { MANAJEMEN }\end{array}$} & $\begin{array}{l}\text { Pengelolaan sediaan farmasi } \\
\text { melalui perencanaan yang baik } \\
\text { didukung kartu stock dan buku } \\
\text { defecta }\end{array}$ & & & & \\
\hline & $\begin{array}{l}\text { Pengadaan sediaan farmasi } \\
\text { melalui jalur resmi sesuai } \\
\text { peraturan undang-undang yang } \\
\text { berlaku }\end{array}$ & & & & \\
\hline & $\begin{array}{l}\text { Penyediaan sediaan farmasi } \\
\text { didukung oleh fasiltas yang } \\
\text { lengkap di apotek }\end{array}$ & & & & \\
\hline & $\begin{array}{l}\text { Membuat penandaan bagi obat- } \\
\text { obat yang } 1 \text { tahun terakhir akan } \\
\text { kadarluarsa (Expired date) dan } \\
\text { memisahkan obat-obat yang } \\
\text { kadarluarsa }\end{array}$ & & & & \\
\hline
\end{tabular}




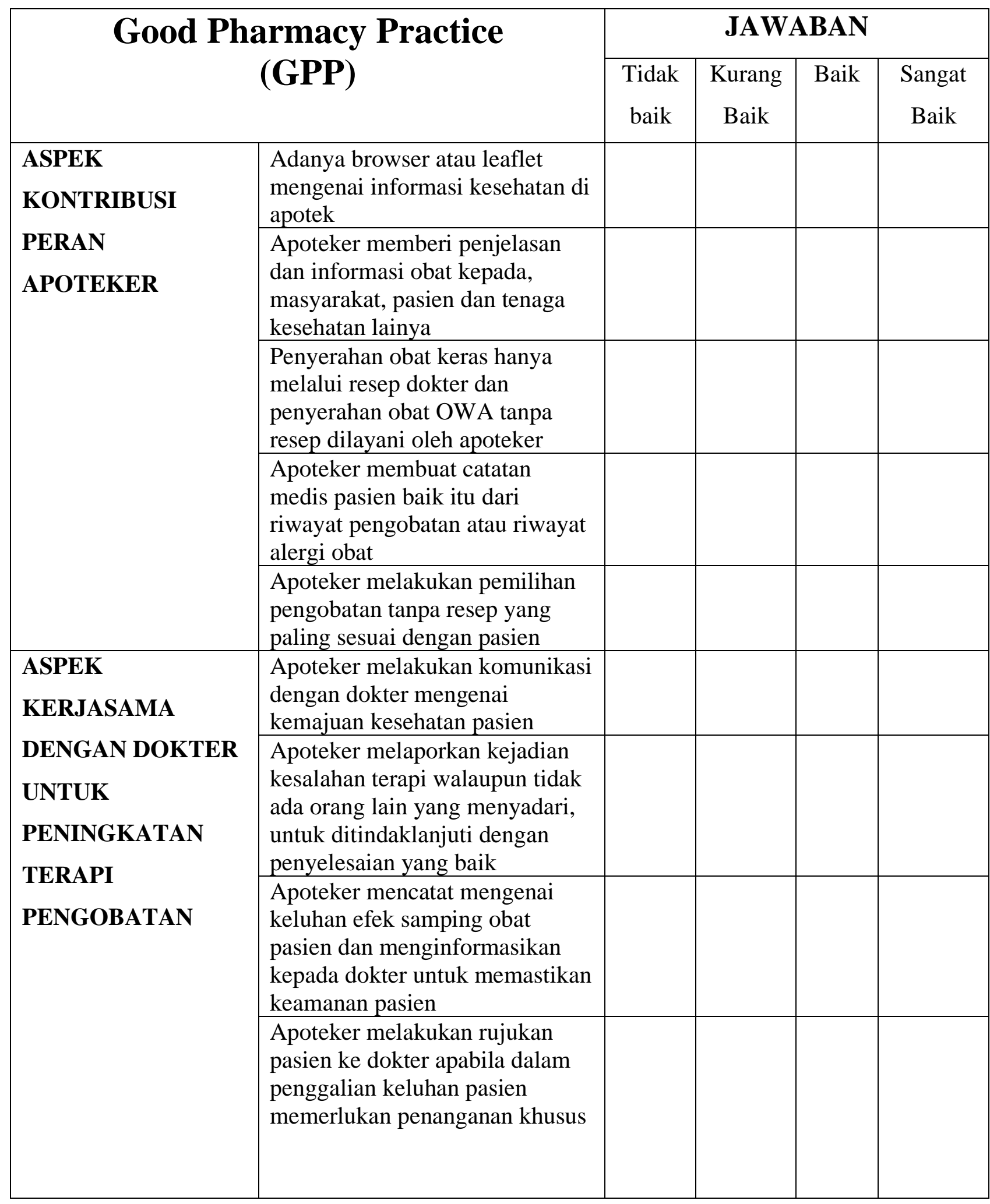

